Discussion Paper No. 02-44

\title{
Flexibility Provisions in Multilateral Environmental Treaties
}

Bernhard Boockmann and Paul W. Thurner

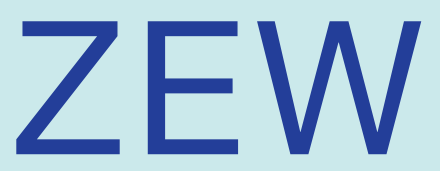

Zentrum für Europäische Wirtschaftsforschung GmbH

Centre for European Economic Research 
Discussion Paper No. 02-44

\title{
Flexibility Provisions in Multilateral Environmental Treaties
}

\author{
Bernhard Boockmann and Paul W. Thurner
}

Download this ZEW Discussion Paper from our ftp server:

ftp://ftp.zew.de/pub/zew-docs/dp/dp0244.pdf

Die Discussion Papers dienen einer möglichst schnellen Verbreitung von neueren Forschungsarbeiten des ZEW. Die Beiträge liegen in alleiniger Verantwortung der Autoren und stellen nicht notwendigerweise die Meinung des ZEW dar.

Discussion Papers are intended to make results of ZEW research promptly available to other economists in order to encourage discussion and suggestions for revisions. The authors are solely responsible for the contents which do not necessarily represent the opinion of the ZEW. 


\section{Non-technical summary}

In this paper, we analyse flexibility provisions in multilateral environmental treaties, such as amendment rules and arbitration procedures, and describe their application in real world settings. Economic contract theory provides the framework for analysis. The advantage of flexibility is that treaties can more easily be adapted to changes in preferences or new scientific knowledge. The disadvantage is that, by introducing more flexible rules for amendment and re-interpretation, countries risk the loss of irreversible investments into the treaty relationship. Therefore, they may be reluctant to enter large-scale international commitments ex ante. The optimal amendment rule weighs advantages and disadvantages of flexibility in a way that ex-ante utility from the treaty is maximised. It depends directly on the degree to which the investment into the contractual relationship is reversible.

In our exploratory empirical analysis, we look at 400 multilateral treaties and supplementary texts from the area of international environmental politics. We note that there are remarkable differences in the provisions for adoption and entry into force of amendments, as well as in the rules for third-party arbitration. Using correspondence analysis, we show that these institutional arrangements can be represented in two dimensions. One is the degree of explicit institutionalisation, the other is the degree of flexibility in collective decision making. Furthermore, it is shown that flexibility rules complement each other. Treaties which have more flexible amendment rules are also more likely to have binding arbitration procedures. This parallels the "checks and balances" applied within nations and suggests that constitution designers care for "bounded flexibility" at the international level.

There is clear evidence that the inclusion of certain provisions has changed over time. While the degree of institutionalisation rises over time, treaties have become successively less flexible since the 1970s. This phenomenon accords well with our contract theoretical treatment of amendment procedures. If treaty obligations to member states have become more substantial during the last couple of decades, and obligations entailed that irreversible decisions had to be made, then countries should indeed have become more anxious to protect these irreversible investments. However, a precise statistical test of our hypotheses is left to further research. 


\section{Flexibility Provisions in Multilateral Environmental Treaties}

\author{
Bernhard Boockmann \\ Centre for European Economic \\ Research (ZEW) \\ P.O. Box 103443 \\ D-68034 Mannheim \\ Tel. +49 621 1235-156 \\ Fax +49 621 1235-225 \\ E-mail: boockmann@zew.de
}

\author{
Paul W. Thurner \\ University of Mannheim \\ Department of Political Science \\ A5 \\ D-68131 Mannheim \\ Tel.: +49 621 181-2066/2067 \\ Fax: +49 621-1812061 \\ E-mail: pthurner@rumms.uni- \\ mannheim.de
}

\section{IINS Research Paper No. 13}

IINS ist eine von der Deutschen Forschungsgemeinschaft finanzierte Forschergruppe.

The research group IINS is financed by the Deutsche Forschungsgemeinschaft (DFG).

Projektleiter / Project Directors:

Dr. Christoph Böhringer, Prof. Dr. Hans-Peter Grüner, Prof. Dr. Beate Kohler-Koch, Prof. Dr. Franz-

Urban Pappi, Prof. Dr. Eibe Riedel, Dr. Paul Thurner, Prof. Dr. Roland Vaubel

\footnotetext{
${ }^{*}$ Sequence of authors follows alphabetical order.
} 


\begin{abstract}
In international politics, intergovernmental treaties provide the rules of the game. Similar to private law, treaty designers face a trade-off between flexibility to adjust to unforeseen contingencies and the danger that the binding nature of the treaty and hence, the level of commitment by treaty members, is being undermined if the treaty can be amended too easily. In this paper, we address this problem in the analytical framework of institutional economics, drawing in particular on the incomplete contracts literature. Furthermore, we derive preliminary hypotheses and operational concepts for the measurement of flexibility in international treaties. Based on 400 treaties and supplementary agreements from the field of international environmental law, we provide new insights into the combined application of rules for adoption and entry into force of amendments, as well as provisions for conflict resolution and interpretative development. Using correspondence analysis, we show that treaty provisions can be represented in a two-dimensional property space, where treaties can be arrayed according to the degree of institutionalisation as well as along a flexibility dimension.
\end{abstract}

\title{
Acknowledgement
}

This work was financially supported by the Deutsche Forschungsgemeinschaft in the framework of the interdisciplinary research group "Institutionalization of International Negotiation Systems". Additional support was provided by Department B of the Mannheim Centre for European Social Research (MZES). We wish to thank Dirk Hanschel for many discussions on the legal aspects of this paper, as well as the members of the research group, Jörg Blasius and Suzumu Shikano for helpful comments. We also thank Benjamin Ohm, Cornelia Weinmann and Gwendolyn Jardine for competent and dedicated research assistance. 


\section{Introduction}

In international politics, intergovernmental treaties provide the rules of the game. Treaties form the constitutions of international relations between the governments committed to them. Like national constitutions, intergovernmental treaties contain only global goals. They constitute frameworks within which concrete solutions can be embedded. An inherent attribute of constitution-building is to declare a consensus on broader goals and to maintain vagueness in order to allow member states to react flexibly in case of changing circumstances. Therefore, intergovernmental treaties never fully specify all the options open to members up to the implementation of operative policies, but include a degree of flexibility through possible modification and reinterpretation of the treaty.

At the centre of this paper are the procedures by which existing treaties can be amended. While a legal basis for amendment and modification is provided by customary law, as well as by the 1972 Vienna Convention on the Law of Treaties, many treaties contain their own rules by which amendments are facilitated, such as majority decision-making. Moreover, subordinate texts to the treaties such as technical annexes or protocols are often subject to different, and easier, amendment rules. Indeed, numerous institutional innovations have emerged in international law, such as framework conventions which formulate only the common interest of the contracting parties, with concrete obligations being developed (and codified) continuously in further negotiation rounds.

Another way of introducing flexibility into international treaties is to formulate them vaguely, but to allow for binding interpretation by dispute settlement bodies as a way of filling the gaps and opening the door for successive development of the treaty (Cooter, 2000, Stone Sweet, 1998, 2000, Vanberg, 1998). The line between treaty development by judicial interpretation and formal amendment is thin. In this paper, we use the existence of dispute settlement procedures as an indicator for the importance of change by interpretation. As Stone Sweet notes, "the implementation of third-party dispute resolution mechanism constitutes one, often privileged mechanism of adapting rule systems to the needs and purpose of live under them" (Stone Sweet, 2000: Preface). Many of these mechanisms will never actually be applied. Nevertheless, their

1 "The separation between an ... authentic interpretation and a treaty amendment is sometimes problematic" (Ipsen, 1999: 115, translation by the authors). For a similar statement, see Amerasinghe (1996: 417). 
mere presence may have a strategic impact on actors' behaviour (Chasek, 2001: 237) and it is, therefore, likely that they are chosen consciously. Ex ante, it is unclear whether arbitration provides an alternative to explicit treaty amendment or whether both ways of including flexibility complement each other. Therefore, both should be looked at in conjunction.

The possibility of amending or re-interpreting a treaty serves to adjust its contents to changing circumstances. However, the fact that a treaty may be renegotiated in the future also gives rise to possible strategic behaviour by governments. In the economic literature, these incentives have been discussed in incomplete contracts literature (for a survey, see Tirole, 1999). Technically, an incomplete contract does not include all relevant information available at the time when it is concluded. For instance, a treaty may not specify contractual consequences for all future contingencies. The result is that the parties may, at some stage, wish to renegotiate the contract. In reality, international treaties are incomplete contracts for a number of reasons. They often specify the obligations of the member states only vaguely, such that it is difficult to assess whether a state is complying with its treaty obligations. Moreover, no clear consequences are stated for many contingencies.

The main problem with contractual incompleteness is that the possibility of future renegotiation may provide an obstacle for the parties to invest in the contractual relationship, because these investments may be a disadvantage at the bargaining table when the treaty is being amended. The argument rests on the assumption that some decisions made in compliance with the treaty are irreversible, such that the costs of compliance cannot be recovered at later stages. We argue that many multilateral agreements, and in particular international environmental treaties, are characterised by the irreversibility of investment decisions.

2 Other important areas of economic contract theory are the principal-and-agent theory, the theory of moral hazard and the theory of incentive-compatible contracts.

3 In the legal literature, the definition of contractual incompleteness is distinct from its use in economics. For lawyers, the crucial point is whether or not the contract contains gaps in its rules, such that the conditions under which the contract obliges the actors to certain actions are not completely specified. "A contract is said to be complete if the list of conditions on which the actions are based is exhaustive, that is, if the contract provides explicitly for all possible conditions. Otherwise, a contract will be referred to as incomplete" (Shavell, 1998:436). From an economic perspective, by contrast, Pareto optimality is a decisive criterion for complete contracts. Even contracts which specify for each state of the world an action to be taken can be incomplete, if the parties have ex post an incentive to renegotiate the contract. 
Recently, Koremenos (2001a, 2001b) has discussed provisions for renegotiation in the framework of an analytical model in the incomplete contracts tradition. She is mainly concerned with the choice of treaties with fixed or indefinite duration. In the case of finite duration, renegotiations on the prolongation of the treaty take place. Otherwise, there are no renegotiations. Koremenos introduces costs of renegotiation, such as costs of organising a meeting, opportunity costs from wasting time in negotiations and the like, as a reason why treaties are not always concluded for a fixed duration. However, Koremenos does not deal with amendment provisions, such as majorities required for adoption or provisions for entry into force.

First, we discuss the requirements of international law concerning the amendment and interpretation of treaties. In the third section, we analyse the costs and benefits of flexibility and discuss different amendment rules from an economic point of view. In the empirical part of the paper, we investigate how amendment rules and third-party arbitration by tribunals are configured in practice, using a data set of 400 multilateral environmental treaties and supplementary agreements. Similar to Koremenos (2001b), we code amendment procedures of existing treaties into a number of categories. ${ }^{4} \mathrm{~A}$ descriptive analysis shows that there is wide variation in the use of amendment provisions and their combinations applied. Moreover, the joint design of different provisions for flexibility in real treaties seem to reinforce each other. We also note that procedures granting greater flexibility are used less frequently in more recent times. Our explanation for this development is that treaties concluded more recently require more irreversible decisions to be made. Hence, treaty-makers were anxious to protect these irreversible investments by choosing less flexible amendment rules.

\section{The Legal Analysis of Renegotiation Procedures}

\subsection{Legal sources of amendment rules}

In international law, treaties are the central legal basis for the commitment of states. Standard textbooks of international law such as Ipsen (1999), Bowett (1982), and

4 Chasek (2001) also codes amendment procedures as part of her "strength index" but uses only 10 treaties as empirical basis.

5 For a critical assessment of the role of international treaties in the context of international lawmaking, see Haffner (1999: 132, translated by the authors): "The explicit formulation of law norms has advantages as well as disadvantages as compared to non-written norms. Advantages, 
Shermers and Blokker (1995) often contain sections on treaty amendment and definitions of the relevant concepts. A starting point are the provisions of the Vienna Convention on the Law of Treaties of 1969. According to Article 39 of the Convention, treaties can be amended by the contracting parties. Unless the treaty provides otherwise, the rules for amendment are the same as the rules for conclusion and entry into force of the original treaty. This means that, apart from treaties adopted at international conferences, amendments are subject to the consent of all contracting parties. In particular, no state can be bound by an amendment to which it has not given its consent (Article 40).

The amendment of a treaty has to be distinguished from a modification as stipulated by Article 41 of the Vienna Convention. Modification means the "changing of particular treaty provisions or even of the whole treaty as agreed upon by a subset of the members, thereby defining only the relationships between subsets of members, so called 'inter-se-agreements', whereas 'amendments' designate a changing of the treaty by all its members" (Ipsen, 1999: 136, translated by the authors). There are a number of conditions connected to treaty modifications which do not apply in the case of treaty amendment. In particular, the position of non-members to inter-se agreements must not be called in question. The requirement is that the modification "does not affect the enjoyment by the other parties of their rights under the treaty or the performance of their obligations" (Article 41.1 (b) (i) of the Vienna Convention). Therefore, amendments adopted and ratified by a majority but not all member states (if the treaty allows for it) are to be distinguished from modifications. In reality, however, this distinction may often be unclear (Ipsen, 1999: 136f.).

With reference to constitutional treaties (i.e. treaties setting up an international organisation or an international regime), Amerasinghe (1996) points out that the application of Article 40 would be particularly problematic if only a subset of the original treaty members declare themselves bound by an amendment:

"In the case of a constitution of an international organization, the constitution would be unworkable, if some amended provisions applied as between group of

because it systematises and integrates existing law, guaranteeing awareness of the norm better verifiability, which results in the prevention of conflicts. As a consequence, states have larger influence in the ongoing active design of international treaties as compared to international common law. ... Disadvantages of codification arise from the fixation of the law at a given point of time, which prevents the dynamic flexibility necessary for adjustment to new conditions." 
members, while conflicting amendment provisions as between another group of members or as between the two groups"(Amerasinghe, 1996: 410) ${ }_{\square}^{6}$

He resolves this problem as follows:

"Short of concluding that constitutions cannot be amended unless specific provision for their amendment has been made, it may be suggested either that amendment is only possible if all the members agree to the amendment - a principle conferring a veto on very single member - or that, while amendment may be possible by agreement among a simple or other majority, those members who refuse to agree to the amendment either cease to be members or must act as if bound by the amendment" (Amerasinghe, 1996: 411).

The latter possibility, however, would be incompatible with the consensus principle inherent in the Vienna Convention, since a group of treaty members could confront the minority with a "take it or leave it"-threat not foreseen at the time the original treaty was concluded.

A further distinction is sometimes made between amendment and revision. If only parts of an existing treaty are changed, the term "amendment" is now accepted, whereas the substantial and encompassing change of a treaty is usually termed as a "treaty revision" (Ipsen, 1999: 136). Nevertheless, since it is difficult in practice to draw a clear line between amendment and revision, the Vienna Convention only uses the term "amendment".

As the development of the treaty by ongoing interpretation is concerned, article 31 of the Vienna Convention refers explicitly to the interpretation of treaties, but is silent as to the interpretation of treaties by arbitration tribunals or other international institutions. Article 66 (a) provides for two different ways of dispute resolution: arbitration (which requires the consent of the parties) and the invocation of the International Court of Justice. Concerning the application of Part V of the Vienna Convention itself, Article 66 (b) provides for a conciliation commission which may issue a non-binding recommendation for the settlement of disputes between contracting parties. However, there are many more institutional varieties when we look at the provisions of individual treaties.

6 These difficulties are reflected in the discussion on "enhanced cooperation" and "flexibility" in European Community Law.

7 For an overview cf. Ipsen (1999: 1021ff.), especially para. 27. 


\subsection{Amendment procedures in international treaties}

If a treaty does not contain explicit procedures for amendment, the provisions of the Vienna Convention provide the rules (Article 40). In this sense, the Convention provides the default rules for treaty amendment. However, as our empirical analysis will show, many multilateral treaties deviate from the rules of the Vienna Convention. Despite the existence of a series of case studies (Schwelb, 1954, Zacklin, 1968, Gold, 1973, Bowman, 1995), little work on these provisions has been done and no general conclusions can be drawn. Only Amerasinghe's (1996: 405-423) study on constitutional treaties provides a systematic presentation and preliminary typology of amendment provisions and their application to real world settings. According to Amerasinghe, most international treaties of constitutional character have provisions for their adjustment. Exceptions are the OECD, the International Telecommunications Union, and the NATO (Amerasinghe, 1996: 406). Some treaties require the investiture of an intergovernmental conference. For instance, the founding treaties of the European Communities require that amendments be adopted by unanimous agreement at an intergovernmental conference, which itself is initiated by a two-thirds majority of

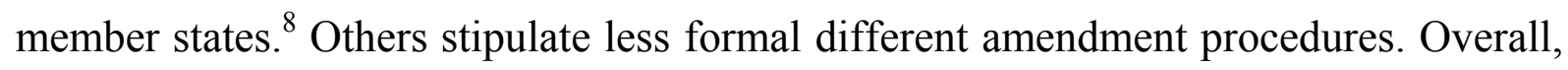
the variety of arrangements and combinations of arrangements appears to be overwhelming.

In a second step, Amerasinghe classifies amendment provisions according to several aspects. One of them is the substance of the amendment. Another is the majority required for the adoption of amendments as well as the provisions for their entry into force (Amerasinghe, 1996: 409). In this context, he distinguishes between a one-step and a two-step procedure for amendment as well as between the consensus versus the majority principle (Amerasinghe, 1996: 412):

"A 'one step' procedure involves adoption of the amendment by an organ of the institution, normally the plenary organ (general congress), which adoption is sufficient to bring the amendment into effect for all members, nothing further being required. The 'two-step' procedure, by contrast, requires, first, that action be taken within the institution by a vote of adoption of the amendment by an organ, generally the plenary or general congress, and second, that the amendment be ratified or accepted by some or all of the member States, before the amendment comes into effect." (Amerasinghe, 1996: 412).

8 Article 96 of the ECSC, Article 236 of the EEC treaty, Article 204 of the Euratom Treaty. 
The one-step or two-step procedures can be applied to different subjects within the same treaty, for instance for the constitutional and the operative parts of the treaty. Which of the procedures is finally chosen also depends, Amerasinghe (1996: 413f.) argues, on whether the majority principle is employed (see below section 3.2).

Amerasinghe also notes differences in the provisions concerning members dissenting with the amendment. Several treaties stipulate that dissenting members must cease to be members of the treaty as amended. Thus Article 26 of the Covenant of the League of Nations stipulated that "those who dissented from amendments once they came into effect ceased to be members of the League of Nations" (Amerasinghe, 1996: 411). Alternatively, dissenting members can be allowed to withdraw voluntarily.

Beside the formal change of treaty provisions, Amerasinghe also covers other flexibility devices. One of these is the "variation" of a treaty, which allows international organisations to adapt a treaty short of formal amendment. This is used, for instance, to increase funding to the organisation (Amerasinghe, 1996: $417 \mathrm{ff}$.). Another way of introducing flexibility is by changing the interpretation of the treaty: "Interpretation of constitutional text may result in a departure from the natural and ordinary meaning of texts... There is a point at which developing a text may result in such change that it amounts to amendment rather than interpretation" (1996: 417), or, even stronger, "The distinction between amendment and interpretation, however, becomes blurred, where practice changes the text of a constitution" (1996: 418). Accordingly, the presence of institutions such as arbitral tribunals or conciliation commissions which structure and institutionalise the process of ongoing interpretation of the meaning of the treaty may be as important an indicator for treaty flexibility as the provisions for formal amendment.

Despite providing interesting and new insights, Amerasinghe's typology and his analytical conclusions are, in our view, preliminary and tentative. In particular, the stages within the process of amendment, such as initiation, adoption, possible ratification by treaty members and, finally, the legal entry into force should be distinguished more systematically, since the overall flexibility of the treaty is jointly determined by the combination of the provisions on all these stages. Furthermore, the empirical identification of typical combinations of flexibility provisions, such as

9 For the discretionary power of constitutional courts in situations of conflicts between separated powers and in cases of constitutional interpretation under given amendment procedures, cf. Cooter (2000: 225-234). 
majority requirements, requirements for entry into force, and the presence of institutions for conciliation and arbitration, is a prerequisite of a positive theory of a flexible adaptive institution-building $\square^{10}$ Based on a theory-guided compilation of empirical facts, results may show that contrary to mainstream convictions in international law as well as in international relations theory in political science there is not necessarily a linear trend of institutionalisation of international law, but the emergence of complex patterns of checks and balances.

\section{The Choice of Flexibility Provisions: A Contract Theoretic View}

In the first part of this section, we discuss the costs and benefits of treaty flexibility, without considering particular institutions or rules. Since the benefits from flexibility are, to a degree, less problematic to deal with, we concentrate on the costs which arise from more flexible treaties. In the second part, we analyse the instruments by which flexibility is actually achieved in international treaties and discuss their interaction.

\subsection{Costs and benefits of flexibility}

In this section, we discuss costs and benefits of flexibility. By flexibility we mean the easiness of changing the contractual obligations under which the parties operate. The benefits of flexibility consist in gains that arise if a treaty can be adapted more easily to changing circumstances. Renegotiation of the treaty may result in the treaty better fulfilling its original purpose - for instance, if new scientific knowledge about the consequences of certain policies has emerged since the time when an international treaty had been concluded. "In this case, renegotiation may result in Pareto improvements from the point of view of the contracting parties. Renegotiation may also prevent the danger of the treaty becoming obsolete or even counter-productive, such that the contracting parties tacitly agree to suspend it. It keeps the treaty members within the boundary of the treaty and makes defection from the treaty less likely (Ress,

10 It should be recalled that Amerasinghe deals only with adoption and entry into force. Many other facets of treaty are not covered in his analysis. This applies, for instance, to institutions for conflict resolution or the possibility of adding protocols and annexes, opening the door to exceptions and refinement without touching the overarching objective of the treaty.

11 Another advantage of flexibility, from the point of view of the individual negotiator, is that it allows for future changes in preferences (Kreps, 1979). However, in a political context negotiators may also have the desire to bind future decision-makers from their own countries in order to prevent the negotiation outcome from being reversed. 
1994: 290). $\square^{12}$ Skilfully designed institutions for renegotiation may induce countries, in the terminology of Hirschman (1970), to voice their objections rather than exit from the treaty. Therefore, less restrictive amendment rules or other flexibility devices may be beneficial.

The costs of flexibility are more difficult to assess. Koremenos (2001a, 2001b) restricts her discussion to costs that arise directly from negotiating amendments. There is no doubt that negotiation costs can be considerable in international treaty systems. However, in our view costs of flexibility are also due to strategic effects, arising from the fact that the binding nature of the treaty and hence, the level of commitment by treaty members, is being undermined if the treaty can be amended too easily. This may lead to less-than-fully-efficient solutions to the underlying economic problem the treaty is meant to solve. The traditional economic law conception of contracts accentuated its function for allowing and securing market exchange. In this view, the most important economic role of contracts is to guarantee the observance of promises. Modern economic approaches, by contrast, highlight the incentives resulting from contracts within different contextual conditions, concerning in particular the distribution of information. On this basis, the question of efficiency - in the sense of the Pareto principle - of contract design is central.

The effect of contract renegotiation on efficiency has been noticed in the scholarly literature in the context of private law. Jolls (1997) discusses the function of contracts as devices of bilateral (rather than individual) commitment. She argues that under certain circumstances - she deals specifically with moral hazard and time-varying preferences, but there may be more - a bilateral commitment not to renegotiate a contract may lead to Pareto improvements ex ante (i.e., at the time when the contract is concluded), although renegotiation clearly must be welfare-improving ex post. Her argument is particularly relevant for international law, because as in common law, an agreement not to renegotiate a treaty cannot be legally enforced if all parties agree to renegotiation.

12 Concerning a related problem, the flexibility of constitutions, a similar point is made by Giovannoni (2001), who considers the benefits and costs of different amendment rules to provide a stable constitution. If amendment is too easy, then the constitution loses its attractiveness. If amendment is too rigidly regulated, then actors in favour of amendments will look for other ways to change the constitution (e.g. revolutions).

13 Indeed, international law is mainly composed of customary law and, thus, has a structure similar to common law (Ress, 1994: 280). Comparing the general notion of contract with the concept of treaty in international law, one recognises a striking analogy. In both cases, transactions between 
The theoretical problem has been dealt with more formally in the incomplete contracting literature. In our view, there are two main problems arising from treaties as incomplete contracts and the incentive to renegotiate contracts. The first is the wellknown hold-up problem, which may arise whenever treaties are renegotiated. The second is limited to particularly flexible amendment rules, such as majority decisionmaking. If negotiators are risk-averse, they have an incentive to under-invest in the contractual relationship, for fear of being in a minority position at the renegotiation stage even if the hold-up problem is not present.

The hold-up problem has been discussed, among others, by Grout (1984), Hart and Moore (1988), Klein, Crawford and Alchian (1978), and Williamson (1985). ${ }^{4}$ In this literature, it is assumed that making a contract work requires parties to invest in the contracting relationship. The important point is that these investments are irreversible in the sense that costs cannot be recovered if the treaty is abandoned, i.e. these investments cause sunk costs. Although the hold-up problem inherent in the renegotiation of contracts has often been analysed in the framework of bilateral exchange relationships between the seller and the buyer of a good, it carries over to a multilateral context as is characteristic for international treaties (Hart and Moore, 1990, Rogerson, 1992). Another important assumption is the absence of a court which observes all the relevant circumstances and, based on this knowledge, imposes a contractually specified solution.

The incentive problem derives from the fact that states which invest heavily in the contracting relationship are always in the danger of being exploited at subsequent renegotiations, because their bargaining position has weakened. Parties which have invested comparatively little may threaten to leave the treaty unilaterally or to stop complying with it, demanding concessions as a price for maintaining the treaty relationship. The hold-up problem arises through non-formal withdrawal from the treaty, which remains an option for the member due to problems of non-verifiability and, in our case, the lack of enforcement at the international level. Therefore, a low level of commitment seems to be preferable in terms of each party's individual rationality. The hold-up problem could be avoided if all contracting parties made a long-run commitment not to renegotiate the treaty (or to limit renegotiation to certain

actors have to be protected by binding agreements. The difference is that the observance of these agreements cannot be guaranteed and enforced by the state or another superior authority. However, despite the lack of enforcing institutions (and perhaps even the lack of reciprocity relations), they assign credibility and legal commitment to the declarations of states.

14 A useful survey of the literature is contained in Schmitz (2001). 
precisely defined circumstances). It could also be avoided if the contracting parties could contract over the degree of compliance and investment, such that the level of compliance could be made a mutually recognisable condition in the renegotiation procedure. However, in the case of international relations it seems clear that none of these theoretical possibilities can be implemented. $\square^{15}$

Some authors have suggested that the hold-up problem can be remedied by including restrictive rules for the renegotiation process into the treaty's governance structure. Aghion et al. (1994) show, for the case of a seller-buyer-relationship, that relationshipspecific investments may reach the efficient level if the parties to the contract commit ex ante to a certain renegotiation design. The renegotiation design which achieves this entails an asymmetric distribution of bargaining power in the case of renegotiation: all bargaining power is given to one party. Second, the "default" solution (in terms of quantities traded) is fixed for the case that renegotiations lead to an impasse. As Nöldeke and Schmidt (1995) show, it may be sufficient that a court can enforce trade of the default quantity, given that the court can observe which party is in breach of the original contract. In international relations, however, a commitment to this kind of renegotiation design seems hardly feasible. In particular, the enforcement of a default solution in the absence of agreement over amendment is not incorporated in the law of treaties. Due to the sovereignty of states, the non-compliance of a state with its obligations can only be sanctioned by suspending treaty relationships with that state. The only feasible default solution is, therefore, the "no trade" situation. Moreover, it is unclear whether the solution to the renegotiation problem proposed by Aghion et al. (1994) and Nöldeke and Schmidt (1995) carries over to the multilateral context.

To our knowledge, the inclusion of more (rather than less) flexible rules than unanimous decision-making for renegotiation, such as majority rules for the adoption of amendments, has not been discussed in the hold-up literature. However, it seems likely that less restrictive procedures, by increasing the chances for successful renegotiation, exacerbate the incentive problem. The problem here is that a party which threatens to leave the treaty or stop complying with it unless the other parties make concessions can play off different groups of members in the renegotiation process. This increases its bargaining power once renegotiations have started. As a

15 First, there is no international court which could prevent the amendment of a treaty if all of the contracting parties agree to it. Second, the level of compliance and investment in the treaty relationship could hardly be verified by such a court. For instance, there is often no clear assessment of the costs and benefits to industry and consumers from the introduction of new, environmentally-friendly technology. 
consequence, members which have made large-scale investments into the treaty face an even greater risk of being exploited than under unanimous decision-making. This provides a further disincentive to invest in the treaty relationship.

The second - and related - problem of flexible amendment rules besides the hold-up problem is also likely to affect the willingness of states to incur sunk investment costs. If amendments can be adopted by majority rule, member states may find themselves in a minority position at the renegotiation stage, hence their returns to the initial irreversible investments may be nullified. The higher the individual initial investment, the greater the amount of resources at the mercy of a majority coalition. Therefore, even if bargaining power at the renegotiation stage is not influenced by the amount of initial investment (as in the hold-up problem), partners to the contract may have a disincentive to invest. While the hold-up problem also exists under risk neutrality, risk aversion is required for the second argument to be valid as a reason for underinvestment. At the constitutional stage where choices over decision rules are made, risk-averse governments, therefore, have a reason to insist on consensus or unanimity if substantial sunk costs are involved.

The existence of sunk costs from compliance with a treaty is crucial for the relevance of both of these arguments. Since international treaties deal with a wide variety of different subjects, a general assessment as to the degree of "sunkness" of the investment cannot be given. However, the presence of sunk costs is often evident in international environmental treaties which form the basis of our empirical investigation. An interesting example, mentioned by Raustiala (2001: 480ff), is the International Convention for the Prevention of Pollution of the Sea by Oil of 1954 (OILPOL), superseded in 1973 by the International Convention for the Prevention of Pollution from Ships (MARPOL). The main instrument of the 1954 treaty was to put limits on the discharge of oil by ocean-going tankers. By contrast, the MARPOL convention introduced certain minimum standards on the equipment of tankers, in particular the requirement for segregated ballast tanks such that ballast water is no longer carried in, and discharged from, cargo oil tanks. The requirement of the OILPOL convention did not necessarily give rise to sunk costs, because it left open how the reduction was to be achieved. By contrast, the provisions of the MARPOL convention require shipowners to equip new tankers with costly new technology. Shipowners cannot recover these costs in case the convention is withdrawn.

16 A model showing this result formally is available from the authors on request. 
In general, international environmental treaties cause sunk costs if they induce polluters to apply new technological measures in the production process in order to reduce the emission of harmful substances, to change the specification of products or to abandon the production of certain products altogether. Other treaties, such as those which restrict maritime fishing activities or limit the economic exploitation of Antarctica or the moon, regulate the use of a common resource. This influences economic decisions over which capacities to hold. Decisions on capacities - such as a reduction of tonnage in the fishing industry - regularly lead to sunk costs, because new physical capital is built up or old production facilities are dumped.

It is reasonable to assume that states take care that the benefits resulting from the adjustment of production technology by all contracting parties will not be dissipated by subsequent renegotiations of the treaty. If there were no sunk costs, the amendment of treaties would be far less problematic because the strategic incentive to under-invest in the contractual relationship would not be present.

On the basis of this argument, we expect that renegotiation rules are more restrictive if sunk costs are more important. While this proposition cannot be tested empirically with our data, two of its implications are testable. First, given that there are explicit flexibility provisions within additional supplementary texts (like protocols, appendixes or annexes) to the treaties, we expect that treaty members more often agree in these supplementary texts on less restrictive (less-than-unanimity) amendment rules. We expect such texts being more focused on specific application areas of the original treaty, implying smaller risks of irreversible investments. Second, given that the obligations specified in international environmental agreements become more specific over time, we expect that treaties adopted later have less flexible amendment procedures.

\subsection{Institutional options in detail}

In this section, we discuss actual amendment procedures and how individual provisions are combined in order to produce the overall flexibility of treaty obligations. Such a discussion is necessary because flexibility is a theoretical concept that cannot be directly observed from the treaty texts. Rather, flexibility arises through the

17 However, within existing treaty systems there may be a countervailing effect: Due to the build-up of trust between the contracting parties, the possibility of strategic opportunism by others is perceived as less of a threat in later than in earlier periods of negotiation. 
combination of different provisions concerning, in particular, the duration of the treaty, the procedures for adoption and entry into force, and the possibility of non-contractual variation of member states' obligations through the application of arbitration procedures. These alternative designs are part of the contractual governance structure which describes the possible actions of the parties in the long-run.

There is a variety of provisions which may influence flexibility. The most important ones are the following:

- A fixed duration of the treaty influences flexibility because the contracting parties have to become active in order to extend the duration at the expiry of the treaty (Koremenos, 2001a). At this point, some of the contracting parties may demand changes to the contents of the treaty, threatening not to participate in the prolongation of the treaty if their demands are not met.

- Some treaties are unlimited, but contain explicit dates for revision conferences. Although this does not preclude amendments to be negotiated outside the revision conferences, it makes renegotiation more likely, since some of the obstacles to renegotiation, such as bringing states' representatives to agree to a date and a place for renegotiation, are removed.

- Adoption and entry into force of amendments follow a diversity of rules. The least flexible approach is to require unanimity of adoption and formal ratification by all contracting parties. More flexible rules are majority voting at the adoption stage and less formal procedures for entry into force or the one-step procedure as described by Amerasinghe (1996).

- Treaties differ in the way non-ratifiers of amendments are treated. Two different provisions can be distinguished. First, non-ratifiers remain bound to the original version of the treaty. This is also the procedure contained in the Vienna Convention. Second, there may be provisions such that non-ratifiers cease to be parties to the treaty. The latter provision clearly provides an incentive to accept the amendment as long as the net benefit from being a member of the treaty are still positive.

- Concerning changes to the obligations by interpretation of the treaty, there may be provisions for bodies which arbitrate between contracting parties in case of conflict. In order to provide for non-violent dispute resolution in case of conflicts about the meaning of the original constitution, treaty members can unanimously ex- 
ante commit to accept the judgement of independent third parties. One may distinguish bodies which can issue binding decisions to the parties to a dispute and those which can only give recommendations.

- In some treaties, there are explicit opt-out provisions which allow countries to be exempt from certain obligations. This may facilitate change. There may also be indirect effects on flexibility by rules on accession to, and withdrawal from, the treaty.

Within these categories, there will often be an intuitive ordering of more or less flexible provisions. For instance, treaties with limited duration are more flexible than those with infinite duration, treaties which specify a date for a review conference are more flexible than treaties which do not, treaties which can be amended by qualified majority are more flexible than those which can be amended only by unanimity. Sometimes, however, the institutional provisions cannot be clearly ordered. For instance, does a provision according to which amendments enter into force upon ratification by a two-thirds majority grant more or less flexibility than a treaty which allows for automatic entry into force of amendments unless a quarter of treaty members object?

Second, we may also have conjectures concerning the comparison of flexibility across each of the categories. For instance, the requirement that all treaty members must ratify an amendment seems to be even more restrictive than the requirement of unanimity at the adoption stage. This is because ratification often involves additional actors at the national level, in particular if ratification requires parliament's assent (the US being a prominent example in this context).

Third, flexibility is produced by combinations of different amendment procedures. Rational decision-makers may not combine treaty provisions which counteract each other. For instance, if the majority rule at the adoption stage were combined with a unanimous ratification requirement, this would lead to the adoption of many amendments which are never actually implemented. In tendency, one would expect the degree of flexibility inherent in individual treaty provisions to complement each other.

The choice of amendment provisions and particular combinations thereof may also be influenced by considerations which are not related to flexibility. An important motivation may be to reduce the costs of renegotiation. By initiating parliamentary procedures, a formal ratification requirement puts a burden on the member states' legislative systems. Therefore, negotiators may prefer to choose the one-step procedure 
for treaty amendment. By contrast, where negotiation costs are expected to be low - in particular, in regional treaties with only a limited number of members - negotiators may have little reason to introduce provisions which make negotiating agreements less costly. Another aspect is that the economic character of the good provided by the treaty may render certain provisions counter-productive. For instance, if the good provided by the treaty is a non-excludable public good, the provision that members not accepting the amendment must leave the treaty is unlikely to be applied, because it would give members a further reason for free-riding.

At the constitutional level, negotiators may also avoid certain combinations of flexibility provisions. An interesting example is Amerasinghe's conjecture that majority decision-making is empirically correlated with explicit ratification requirements (see table 1). While Amerasinghe provides no arguments for his conjecture, a plausible rationale may proceed along the following lines. The possibility of modifying a treaty by majority rule implies that the original members commit ex ante to be - at least potentially - forced to accept amendments which have negative externalities on the minority coalition. Since the unanimity status quo ensures each member its full property rights, such a decision entails the risk of a loss of autonomy and self-determination of an actor and therefore a change of regime from a set of actors with full autonomy to a set of actors with reduced and enhanced autonomy, respectively. Under incomplete information and once members have accepted the risk of majority-based renegotiation, members have a preference to make sure that amendments are actually implemented. This implementation occurs formally by ratification, and practically by complying members. Thus, rather than making renegotiation more difficult, a formal ratification requirement may also serve as a device to make sure which contractual obligations (those of the amended treaty or those of the original treaty) apply to each of the parties and commit members to the implementation of the amendments.

Table 1: Amerasinghe's Conjecture

\begin{tabular}{lcc}
\hline & \multicolumn{2}{c}{ Procedure for entry into force } \\
\cline { 2 - 3 } Procedure for adoption & One-Step & Two-Step \\
\hline Unanimity & $\mathrm{X}$ & - \\
Majority & - & $\mathrm{X}$ \\
\hline
\end{tabular}


Concerning another example, the interaction between explicit amendment and dispute resolution, one would expect that the presence of strong third party conflict resolution mechanisms coincides with the possibility to amend the treaty with less than unanimity. There are two reasons for this. On the one hand, if amendments can be made by majority, countries may wish to introduce an institutional actor having the power to review amendments and to mediate in the case where a majority has caused negative externalities to the original treaty members. Arbitration, then, genuinely constitutes a flexibility provision on its own by transferring these institutions the right of interpretation, and it is linked to another flexibility device, namely majority voting. On the other hand, given that the discretionary leepvay of these bodies is limited by the size of the Pareto set of the conflicting parties, ${ }^{48}$ and the Pareto set is the larger the greater the majority required for changes, unanimity may endow tribunals and commissions with more power than desired by states. Therefore, actors establishing such provisions simultaneously have an interest to confine the power of such tribunals, "... lowering the obstacles to change the constitution, such as requiring a simple majority instead of a supramajority, decreases the discretionary power of the courts to interpret the constitution" (Cooter, 2000: 232).

This discussion of possible interaction effects in the choice of amendment provisions is certainly not exhaustive. However, we now turn to the empirical evidence concerning which amendment provisions (and combinations of them) are actually chosen in realworld treaty systems.

\section{Empirical analysis of flexibility provisions}

In this section, we present a descriptive data analysis of flexibility provisions in multilateral environmental treaties. Given that there have been no previous empirical studies on the subject, we restrict ourselves to simple description and bivariate testing of hypotheses. The questions driving the exploratory data analysis are the following:

- What is the proportion of multilateral environmental treaties actually having flexibility provisions? Are there different provisions within treaty systems, such as differences between the main text and treaty annexes?

18 For the setting of separated powers systems cf. Cooter (2000: 225). 
- How is flexibility achieved and which of the institutional variants, such as provisions concerning duration, adoption, ratification, third party conflict resolution, accessibility, are empirically identifiable?

- Which combinations are typically used? Which combinations do not occur? Are combinations of provisions for adoption, entry into force and dispute resolution etc. obviously chosen in order to reinforce each other or do they thwart each other? Can we detect a latent joint pattern behind the combination of flexibility provisions?

- Do supplementary texts have more flexible provisions for renegotiation than main treaty texts?

- Are there changes in flexibility over time?

For the reason discussed in the last section, we concentrate on environmental treaties in the empirical analysis. The data set includes only multilateral treaties. Our strategy is to sample all "important" environmental treaties, because these are most likely to involve economic costs. In judging whether a treaty is important, we rely on experts' judgements. The criterion is inclusion of the treaty in the collection of Burhenne (n.d.). Burhenne groups treaties into a number of subject categories. Since the number of treaties in the Burhenne collection is very large, we restricted the sample to the following subject categories which form the core of international environmental concerns: air; atmosphere, climate and outer space; environmental conservation (general); hazardous substances; natural resources and nature conservation; non renewable resources and mining; seawater quality and pollution; and water quality and pollution. These represent eight of a total of 35 subject categories. however, are classified in more than one subject grouping. Therefore, most overarching environmental treaties dealing with more than one environmental problem are represented in our data.

We use all treaties contained in these subject groups from Burhenne's treaty collection, as well as all supplementary agreements such as protocols, annexes or appendices. Clearly, our sample is not meant to be representative for the universe of environmental treaties, let alone for all international agreements. The number of treaty texts in our sample is 400 . Of these, all but 35 texts are obtained from internet sources and are thus

19 However, many of the subject categories not used in the sample contain only very few treaties. 
machine readable. The others are taken from the United Nations Treaty Collection (UNTS) or, in case they are not included there, directly from the Burhenne collection.

An entry in the data set consists of a text or supplementary text which is subject to a certain amendment procedure. That means that texts are not classified according to the provisions they contain, but according to the provisions by which they are affected. Thus, if the amendment procedure of an appendix to a treaty is contained in the main text of the treaty, information is taken from the main text. In 13 cases, parts of a text were subject to a different amendment procedure than other parts of the treaty. In this case, parts with different procedures form separate entries in the data set.

Given that the data base consists of treaties, protocols, annexes and the like, there is a hierarchy of texts. Of all texts, 102 are separate treaties and 298 are supplementary texts to these treaties. We distinguish between main texts, protocols (explicitly named in this way), ${ }^{20}$ level 1 supplementary texts (i.e., annexes or appendixes to treaties or protocols) and level 2 supplementary texts (i.e., appendixes to annexes). Supplementary texts may be adopted at the same time or later than the superordinate text. The number of texts in each category of texts can be seen from table 2 .

Table 2: Categories of treaty texts

\begin{tabular}{lccccc}
\hline & Treaties & $\begin{array}{c}\text { Treaty } \\
\text { Parts }\end{array}$ & Protocols & $\begin{array}{c}\text { Level 1 } \\
\text { supp. } \\
\text { texts }\end{array}$ & $\begin{array}{c}\text { Level 2 } \\
\text { supp. } \\
\text { texts }\end{array}$ \\
\hline $\begin{array}{l}\text { Number of texts } \\
\text { Amendment provisions differ } \\
\text { from those of superordinate text } \\
\text { (in \%) }\end{array}$ & 102 & 13 & 40 & 221 & 24 \\
\hline \hline
\end{tabular}

20 The distinction between a main treaty and a protocol is often considered to be arbitrary by international lawyers and has no legal consequences (Ipsen, 1999: 98). Usually, however, protocols explicitly refer to an already established treaty. They may borrow their amendment provisions from this treaty, which is why we use a separate category for protocols. 
The content analysis of the texts was based on a keyword search of terms relating to flexibility provisions. ${ }^{21}$ The passages containing the legal provisions were then classified according to a code book. The code book contains entries on the following aspects: subject category according to Burhenne; year of adoption; original number of contracting parties, if given in the treaty (used as a control variable); definite-term or indefinite-term agreement; revision of the treaty mentioned (yes/no) and length of period until first revision; amendment mentioned (yes/no); procedure for adoption of amendment; procedure for entry into force of amendment; provisions concerning treaty members dissenting with amendment; institutions for arbitration; bindingness of arbitration (yes/no); scope of the arbitration procedure (complete text or parts of the text). The code book is reproduced in the appendix to this paper.

\subsection{Univariate analysis}

With respect to a number of variables collected, we find that the environmental treaties of our sample are quite similar. First, all of the treaties or supplementary texts are, either explicitly or implicitly, unlimited in duration. Second, only 11.2 per cent of the texts specify in advance a date for possible revision. Third, 82.5 per cent of all treaties do not mention the original members of the treaty or limit the treaty to a particular group of countries. Fourth, only 28 texts explicitly mention the position of signatories which do not accept an amendment. In 21 of these cases, a provision is included stipulating that these members must leave the treaty altogether. ${ }^{2}$ This confirms our expectation that in public goods treaties exclusion is rarely used as a threat in order to facilitate amendment or to ensure the uniformity of treaty texts. Finally, only 13 texts limit the scope of the arbitration procedures to particular designated parts of the

21 Keywords referring directly to amendments were the following: amendment, modification, alteration, change, revision and its different lexicographical modifications. As keywords referring to arbitration, we used arbitration, tribunal, judicial, mediation, dispute, settlement, conciliation. We also looked in the wider area of flexibility provisions using the keywords contracting out, opt-out, annulment, termination, suspension, renunciation, withdrawal, termination of membership, escape clause, inter-se. We used a coding procedure whereby an international law students coded each case. After an initial instruction period, the coding proved to be reliable and were only checked randomly by the authors.

22 In other parts of the code book, we did not distinguish between revision and amendment, since these terms are often used synonymously.

23 These are mainly treaties establishing international organisations or regimes, such as the Antarctic Treaty or the Convention on the International Consultative Maritime Organisation. Hence, we find support for Amerasinghe's notion (mentioned earlier) that it is essential for constitutional treaties to ensure that the same treaty applies to all member states. 
agreement. We, therefore, limit the following investigation to three kinds of provisions where the variation observed in the sample is greatest: adoption of amendments, their entry into force, and procedures for dispute settlement.

Next, we investigate whether supplementary texts deviate in their flexibility provisions from the superordinate texts. If supplementary texts only reproduced the governance structure of the main treaty texts, it would be reasonable to limit the empirical analysis to the latter. However, we observe from table 2 that supplementary texts quite frequently contain amendment procedures which differ from the amendment procedures of the superordinate text. This is most evident in the case of protocols, of which more than a third have provisions which differ from those of the main treaty text. Sometimes, however, this reflects the fact that the protocol is, in fact, a new treaty, such as the Protocol on Environmental Protection to the Antarctic Treaty of 1991, which was adopted over thirty years after the original treaty, or the Montreal Protocol on Substances that Deplete the Ozone Layer. Others, such as the Protocol for the Protection of the Mediterranean Sea against Pollution from Land-Based Sources of 1980 are more closely associated to the original treaty. Hence, there is more heterogeneity in this group of texts than in the others.

In our data, we find a huge number of institutional variants concerning flexibility provisions for adoption, entry into force and dispute settlement. ${ }^{24}$ There is clearly a trade-off between preserving the richness of the institutions of the real world, on the one hand, and the need to reduce them to a limited number of ideal typical arrangements in order to discover regularities in their use, on the other. We solve this problem by aggregating the institutional options into the broader categories shown in tables 3 to 5 .

24 In many cases, requirements are quite complex, for instance if a majority is defined both in terms of the number of states as well as in their importance to the problem - such as tonnage for treaties concerning the pollution of the sea. Other treaties, like the Antarctic Treaty, distinguish between different groups of member states with different weights in the decision procedure. Some treaties, especially regional ones, express the majority requirements in absolute numbers rather than proportions. 
Table 3: Provisions for adoption (per cent of all texts)

\begin{tabular}{lccccc}
\hline & Treaties & $\begin{array}{c}\text { Treaty } \\
\text { Parts }\end{array}$ & Protocols & $\begin{array}{c}\text { Level 1 } \\
\text { supp. } \\
\text { texts }\end{array}$ & $\begin{array}{c}\text { Level 2 } \\
\text { supp. } \\
\text { texts }\end{array}$ \\
\hline 1 Unanimity & 15.7 & 23.1 & 10.0 & 13.1 & 0.0 \\
2 Consensus & 11.8 & 15.4 & 22.5 & 29.0 & 37.5 \\
3 Qualified majority & 33.3 & 53.8 & 42.5 & 41.2 & 58.3 \\
4 Not specified & 39.2 & 7.7 & 25.0 & 16.7 & 4.1 \\
\hline \hline
\end{tabular}

$\chi^{2}$-statistic: 40.8 (p-value: 0.000$)$

From the first column of table 3 , we observe that a third of all main treaty texts allow for majority decision-making on amendments. In all but nine cases, this means qualified majority voting by majorities of either two-thirds or three-quarters. About one out of four treaties explicitly grants veto power to each member state, with the consensus rule as a softer form of unanimity. Almost forty per cent of treaties do not mention flexibility provisions at all or leave the amendment rule unspecified. Here, the Vienna Convention as a fallback provides the rules for amendment, which means unanimous decision-making. ${ }^{5}$ As far as the supplementary texts are concerned, our tentative hypothesis is confirmed: supplementary text are generally less restrictive than main treaty texts. According to the chi-squared statistic, the difference between main treaty texts and supplementary texts is highly significant. Also interesting is that supplementary texts more often contain specific amendment procedures than treaties. This is because treaties with an array of supplementary texts are more institutionalised entities than stand-alone treaties, and the degree of institutionalisation carries over to the supplementary texts.

25 However, in cases of conflict the explicit definition of unanimous renegotiations may result in lower transaction costs as compared to treaties amended in accordance with the Vienna Convention. 
Table 4: Provisions for entry into force

\begin{tabular}{lccccc}
\hline \hline & Treaties & $\begin{array}{c}\text { Treaty } \\
\text { Parts }\end{array}$ & Protocols & $\begin{array}{c}\text { Level 1 } \\
\text { supp. } \\
\text { texts }\end{array}$ & $\begin{array}{c}\text { Level 2 } \\
\text { supp. } \\
\text { texts }\end{array}$ \\
\hline $\begin{array}{l}\text { 1 All have to ratify } \\
\text { 2 A qualified majority has to } \\
\text { ratify }\end{array}$ & 64.1 & 46.2 & 60.0 & 40.7 & 12.5 \\
$\begin{array}{l}\text { 3 No ratification, but objection } \\
\text { is possible }\end{array}$ & 2.9 & 15.4 & 2.5 & 17.2 & 70.8 \\
$\begin{array}{l}\text { 4 No separate ratification } \\
\text { procedure }\end{array}$ & 6.9 & 15.4 & 2.5 & 16.7 & 12.5 \\
\begin{tabular}{l} 
5 Not specified \\
\hline
\end{tabular} & 39.2 & 7.7 & 25.0 & 16.7 & 4.2 \\
\hline
\end{tabular}

$\chi^{2}$-statistic: 105.3 (p-value: 0.000$)$

Concerning provisions for entry into force (table 4), only few multilateral treaties require all parties to ratify amendments. In all other cases, either ratification of a majority of member states is sufficient for entry into force or entry into force of amendments does not require formal ratification. The third row contains those cases where the treaty enters into force automatically unless a specified number or proportion of member states raises objections. As one would expect, ratification is more often used for main treaty texts and protocols, while automatic entry into force is a provision most often found in supplementary texts. In particular, the simplified procedure whereby an amendment enters into force unless objections are raised almost becomes the norm for level 2 supplementary texts. The fourth row contains cases where the

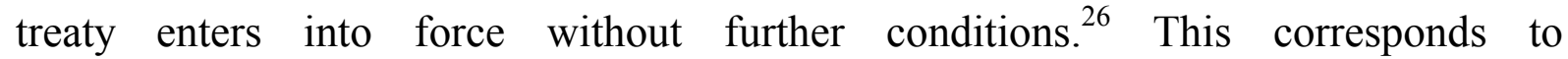
Amerasinghe's one-step procedure. Overall, only a small fraction of sample texts contain such a provision. Again, the absence of a specification for entry into force means that the provisions of the Vienna Convention apply. Our hypotheses of supplementary texts showing less restrictive flexibility provisions is again significantly corroborated by the data.

26 In some cases, the amendment enters into force only for those states which do not object to being bound by the amended treaty. In others, no objections are admissible. 
Table 5: Provisions for arbitration

\begin{tabular}{lccccc}
\hline & Treaties & $\begin{array}{c}\text { Treaty } \\
\text { Parts }\end{array}$ & Protocols & $\begin{array}{c}\text { Level 1 } \\
\text { supp. } \\
\text { texts }\end{array}$ & $\begin{array}{c}\text { Level 2 } \\
\text { supp. } \\
\text { texts }\end{array}$ \\
\hline 1 Binding arbitration & 26.5 & 53.8 & 37.5 & 48.9 & 62.5 \\
2 Non-binding arbitration & 19.6 & 23.1 & 27.5 & 29.9 & 25.0 \\
3 No arbitration & 53.9 & 23.1 & 35.0 & 21.3 & 12.5 \\
\hline \hline
\end{tabular}

$\chi^{2}$-statistic: 41.9 (p-value: 0.000$)$

With regard to the provisions for dispute resolution (table 5), we distinguish between tribunals issuing binding decisions and bodies which give recommendations only. If a treaty contains both kinds of provisions, we code it as having binding arbitration. We observe that more than half of the treaties do not provide for institutions for dispute settlement at all. On the other hand, supplementary texts show significantly more stringent dispute settlement procedures, more than half of them having binding arbitration.

\subsection{Bivariate and multivariate analysis}

In the following table, we describe the most frequent combinations of flexibility provisions. This should give a first impression on whether provisions in one category, such as adoption provisions, are complemented by provisions in another, i.e. entry into force or arbitration procedures. Moreover, we can verify the conjectures about combinations of provisions derived in section 3. As an empirical basis, we consider the full sample of 400 treaty and agreement texts.

The most frequently used combination consists in the absence of rules in all three types of provisions we consider. This mainly concerns treaties adopted from the 1950s to the 1970s. In most cases where a majority is sufficient for adoption, we also find provisions for binding arbitration (lines 2, 5 and 8). We interpret the existence of binding arbitration as an ex-ante protection against profound changes in existing treaty texts brought about by majority rule. As soon as treaty members renounce unanimity, tribunals may be used to protect against unwanted consequences of more flexible provisions. Conversely, there are a considerable number of cases where binding arbitration goes together with consensus or the fallback provisions (lines 3, 6 and 15). 
In particular, the combination of binding arbitration with the default solution of the Vienna Convention for amendment and entry into force gives arbitral tribunals maximum power to change treaty obligations without being threatened by explicit amendments by states. This does not give strong support to the view that states are anxious to limit the discretionary leeway for interpretation, as argued by Cooter (2000).

Table 6: Most frequent combinations of flexibility provisions

\begin{tabular}{llllr}
\hline Rank & Adoption & Entry into force & Arbitration & No. of cases \\
\hline 1 & not specified & not specified & no arbitration & 60 \\
2 & majority & a majority ratifies & binding & 58 \\
3 & consensus & a majority ratifies & binding & 31 \\
4 & consensus & a majority ratifies & no arbitration & 23 \\
5 & majority & if no objections & binding & 20 \\
6 & not specified & not specified & binding & 19 \\
7 & consensus & if no objections & non-binding & 18 \\
8 & majority & one-step & binding & 17 \\
9 & consensus & all ratify & non-binding & 15 \\
10 & majority & if no objections & no arbitration & 14 \\
11 & consensus & a majority ratifies & non-binding & 13 \\
12 & unanimity & all ratify & no arbitration & 10 \\
13 & unanimity & a majority ratifies & no arbitration & 10 \\
14 & not specified & not specified & non-binding & 10 \\
15 & consensus & one-step & binding & 10 \\
\hline
\end{tabular}

Amerasinghe's (1996: 413) conjecture according to which a majority requirement at the adoption stage necessitates a further ratification stage is contradicted by 17 texts which combine qualified majority voting with the one-step procedure (line 8 ). These cases appear to be particularly interesting because here, a majority of treaty members make decisions which become, without further conditions, binding on all states. However, the one-step category comprises also the possibility that states can 
individually object to an amendment, with the consequence that the amendment does not become binding on them, but without calling into question the legal entry into force of the amendment: $\square$ We found only one case among those included in line 8 where such an opt-out provision was not included. $\square^{28}$

The most restrictive amendment procedure from the table is contained in line 12 (unanimity, all members have to ratify, no arbitration). It applies to the following three treaties, including their supplementary texts: the Agreed Measures for the Conservation of Antarctic Fauna and Flora of 1964, the Agreement for Cooperation in Dealing with Pollution of the North Sea by Oil and Other Harmful Substances of 1983 and the Cooperation Agreement for the Protection of the Coasts and Waters of the North-East Atlantic Against Pollution of 1990. According to our theory, these should be treaties where sunk costs are particularly important. While this is very hard to see in the first case, the other two treaties do contain provision which require member states to undertake irreversible investments. The Agreement of 1983 call on states to provide techniques to monitor oil pollution. The Cooperation Agreement of 1990 requires states to set up and maintain in operation equipment in order to be able to deal with discharges of hydrocarbons or other harmful substances.

In the next step, we apply correspondence analysis to describe more completely the interaction of different flexibility provisions. The aim is to recover the dimensionality of the data. We are interested in whether the variety of flexibility provisions and their combinations are reducible to a common underlying property space. Correspondence analysis is an exploratory method for finding out lower-dimensional mappings of discrete data tables (Greenacre, 1993, Clausen, 1998, Blasius, 2001). The institutional provisions contained in tables 3 to 5 are entered as nominal, rather than ordinal, categories in order to preclude any arrangement of the data that should be the result of the dimension reducing technique. The extracted spaces are defined according to a chisquared distance concept. We use bivariate correspondence analysis of a composed table. The column variable is the procedure for adoption of amendments, which is regarded as the central variable of interest since it determines whether all parties have given their consent to amendments. The rows are formed by the procedures for entry into force and for arbitration. ${ }^{20}$ We display combined biplots, i.e. row and column

27 See Appendix.

28 Statutes of the International Union for Conservation of Nature and Natural Resources (as amended), 1948.

29 This procedure is usually practised following the application in Bourdieu (1984). 
points are in a single map. Standardisation is symmetrica $\square^{30}$ It is important to keep in mind that even with a symmetrical standardisation one cannot, in contrast to the use of Euclidean distance metric in factor analysis, exactly interpret distances between row and column points, respectively, as similarities. However, it is possible to draw conclusions from the clustering of variable values, because row points that are close to each other can be interpreted as being similar as compared to the distribution of cases across the columns.

Figure 1: Correspondence analysis of flexibility provisions - all texts

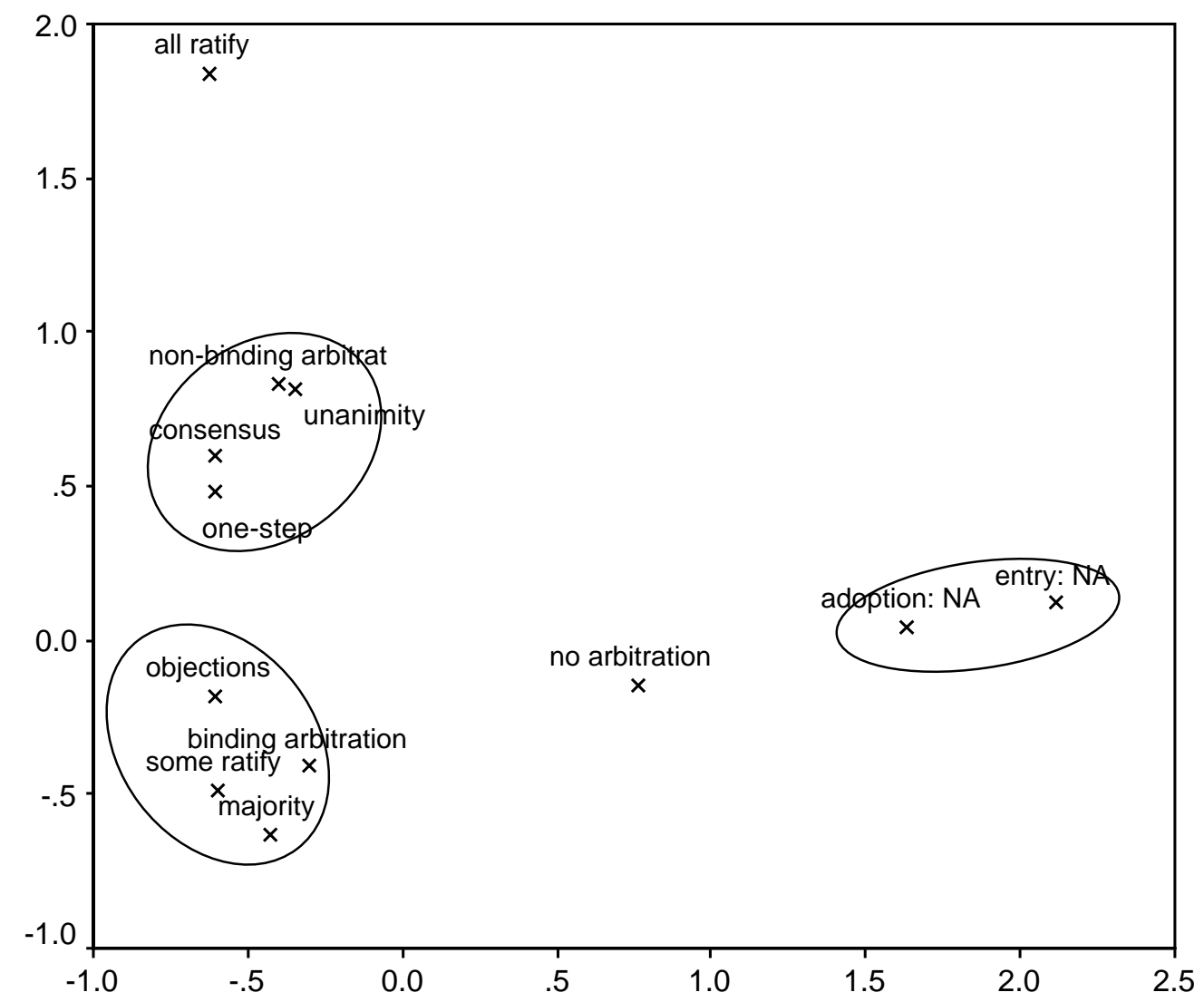

Turning to the results shown in figure 1, we conclude from the Eigenvalues that two dimensions are sufficient to explain the variation in flexibility provisions. The first and second dimensions together explain about 70 per cent of the inertia. While according to

30 Standardising only on rows and columns, respectively, led to identical results. 
a chi-squared test, a third dimension would contribute significantly to the explanation of inertia, we decided to leave it out because it contributes only four percentage points to the total inertia explained.

The dimensions of the graph have a clear prima facie interpretation. The $x$-dimension, explaining about 60 per cent of inertia and accounting for about 84 per cent of the total inertia, can be viewed as the degree of explicit institutionalisation. Provisions to the left of the graph are institutionalised options, while the absence of explicit provisions is located at the right. The $y$-dimension, by contrast, can be interpreted as indicating the degree of flexibility in decision-making.

The more important institutionalisation dimension extends from the implicit default solution for adoption on the one pole (contributing the most to the inertia of this dimension) to the group of explicit provisions on the other. The absence of provisions for adoption or entry into force renders a treaty even less institutionalised than a treaty which does not include a procedure for dispute settlement. The second dimension extends from the requirement that an amendment must be ratified by all treaty members to the majoritarian amendment rules. The result that the requirement for all contracting parties to ratify amendments is ranked as least flexible is not surprising in the light of our a priori considerations (see section 3.2). With some distance, the adoption of an amendment by unanimity or by consensus is also identified as a requirement inhibiting flexibility. Binding dispute settlement has the same coordinate in the $y$-dimension as the majoritarian amendment provisions. Overall, the provisions for arbitration fit remarkably well into the two dimensions. Treaties without amendment procedures have a low degree of institutionalisation, while the bindingness or otherwise of the arbitral judgement determines the position in the flexibility dimension. Binding arbitration may be associated with majoritarian decision-making (i.e., flexible rules) for the reasons discussed above. Alternatively, a tribunal issuing binding judgements contributes on its own to flexibility, since the scope for the development of the contractual obligations is enhanced.

One-step procedures which do not have an independent procedure for coming into force are located at an intermediate degree of flexibility. One might argue that the absence of any ratification stage is the most flexible provision for entry into force. In practice, however, one-step procedures are frequently combined with the consensus requirement at the adoption stage. Here, there could be another dimension at work: both consensus and the one-step procedure could be chosen for treaties which are not 
particularly important in terms of member states interests and for which, thus, the costs of coming to an agreement are held minimal.

\section{Figure 2: Correspondence analysis of flexibility provisions - treaties and protocols}

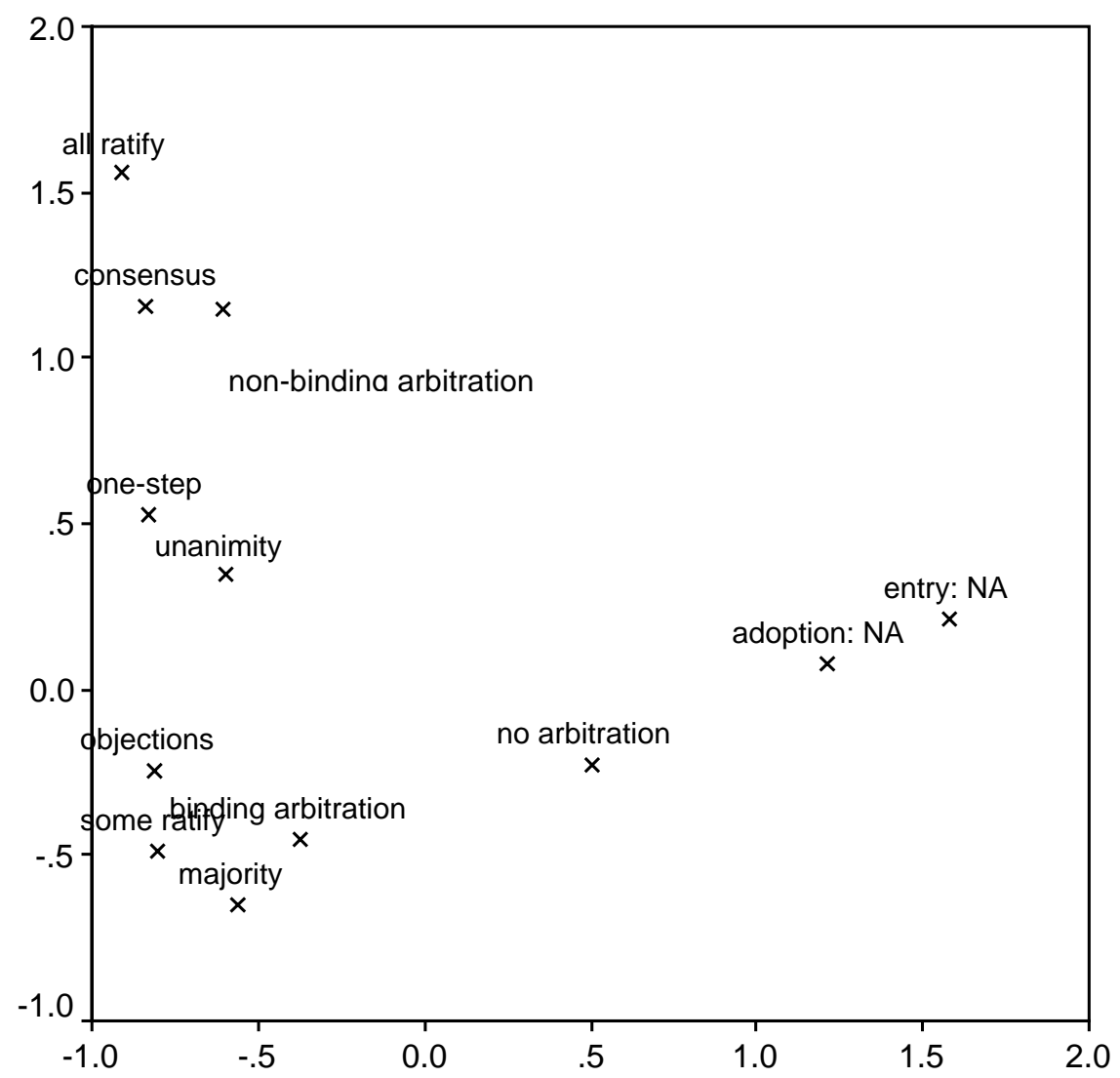

Next, we repeat the analysis for the group of main treaty texts and protocols. The inclusion of all supplementary texts could result in a too high a weight being given to provisions from treaties with many supplementary texts, since in some cases the supplementary texts just reproduce the provisions from the main text. The results from figure 2 show that the coordinates of the provisions show little change compared to the full sample. Somewhat counter-intuitively, however, consensus and unanimity at adoption change places. This may perhaps reflect the reduction of the overall number of observations, rather than structural differences between different groups of treaties. 
In a further step, we introduce two groups of passive variables, the year of adoption of the text and the position of text in the hierarchy defined in tables 3 to 5. Passive variables can be located in the same dimensions as the flexibility provision, while they do not influence the coordinates of the active variables (see Clausen 1998, Blasius 2001).

Figure 3: Text hierarchy used as passive variable - all texts

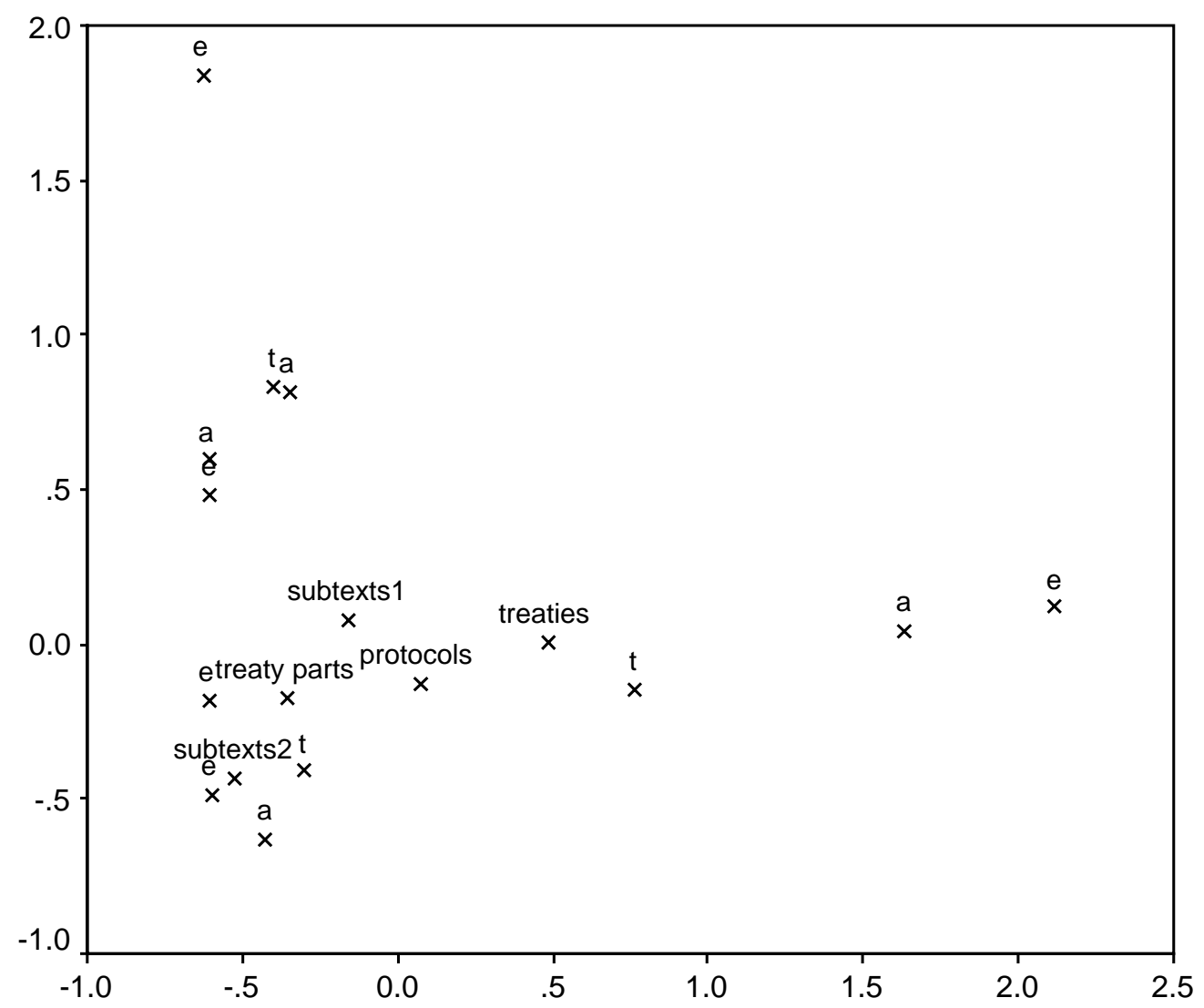

Figure 3 shows the location of texts at different hierarchy stages in the institutionalisation and flexibility dimensions. The positions of the different flexibility provisions are the same as in the previous figures, with "a" designating an adoption procedure, "e" a procedure for entry into force and " $\mathrm{t}$ " a rule on arbitration. We observe that main treaty texts are found to be less institutionalised than supplementary texts. This may be implied by the construction of the data: if a treaty contains amendment procedures, they usually extend to appendixes and annexes, too. More interesting are the differences in the flexibility dimension. If the treaty contains parts subject to different amendment procedures, these articles contain more flexible 
provisions. Supplementary texts on the first hierarchy level are not different from the main treaty texts with respect to flexibility. However, supplementary texts on the second hierarchy level do possess more flexible provisions.

Figure 4: Date of adoption used as passive variable - all texts

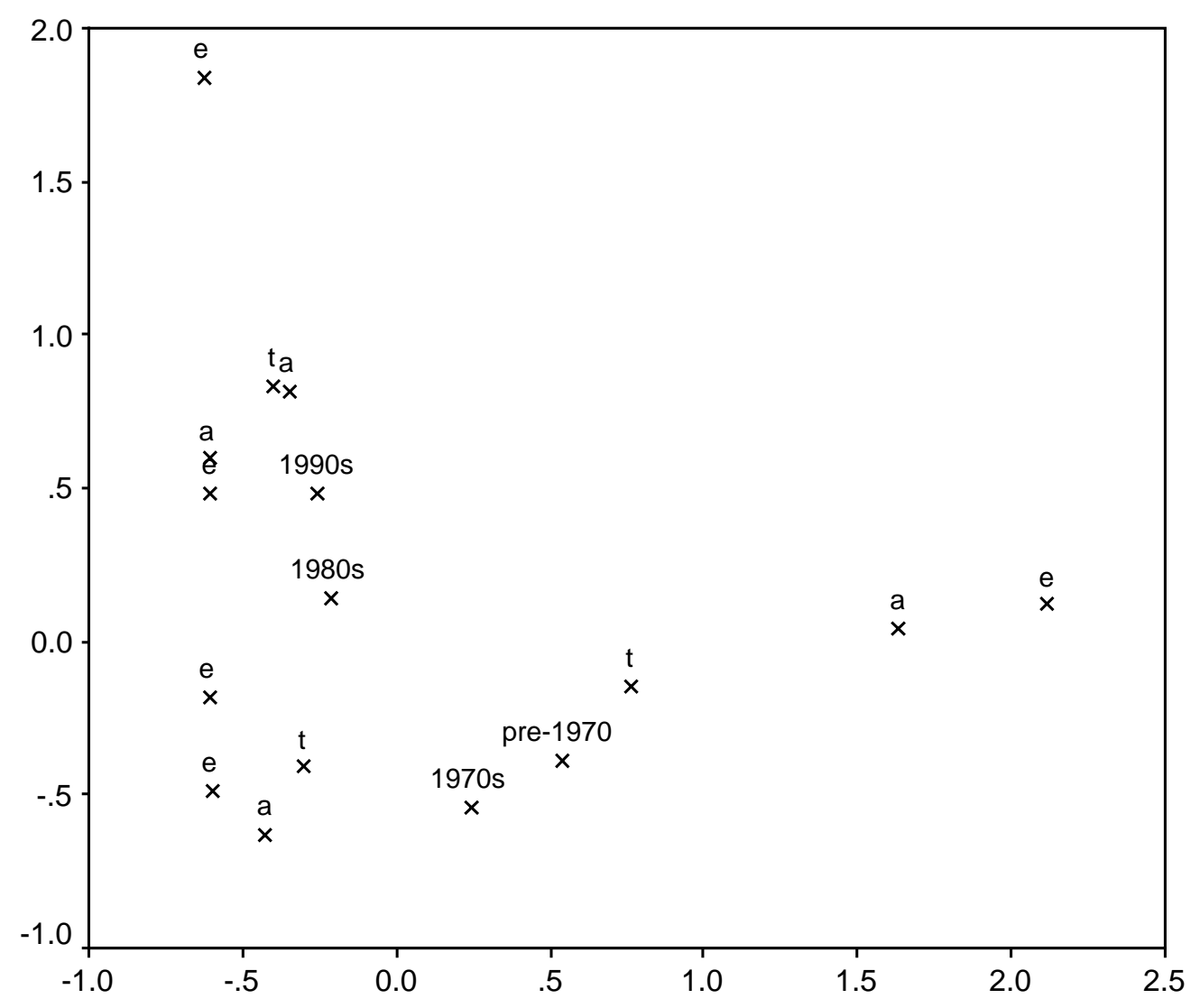

Taking the year of adoption as a passive variable (figure 4), we note that the degree of institutionalisation has increased over time, albeit this development seems to have come to an end in the 1980s. In the flexibility dimension, there is a marked change between treaties adopted in the 1970s and treaties adopted after 1990. Treaties adopted earlier show a much higher degree of flexibility, being positioned at the same $y$ coordinate as the majoritarian provisions for adoption and entry into force. By contrast, treaties from the 1990s are positioned at the same flexibility coordinate as the consensus rule. Given that environmental treaties adopted later contain more substantive and less symbolic content (Congleton, 1992), this finding accords well with our theory. In our view, the more restrictive rules contained in the treaties of the 1990s 
serve to protect the irreversible decisions required by the treaties adopted during this decade, while negotiators had to be less apprehensive concerning the dangers of renegotiation in earlier periods.

\section{Conclusions}

In this paper, we have analysed flexibility provisions in multilateral environmental treaties and described their application in real world settings. Coming from a contract theory perspective, we have stressed that the flexibility provisions included in international treaties have economic significance. The advantage of additional flexibility is that treaties can more easily be adapted to changes in preferences or new scientific knowledge. The disadvantage is that, by introducing majority rules for amendment and the like, countries risk the loss of their irreversible investments into the treaty relationship. Therefore, they may be reluctant to enter large-scale international commitments. The optimal amendment rule weighs advantages and disadvantages of additional flexibility in a way that ex-ante utility of the treaty is maximised. It depends directly on the degree to which the investment into the contractual relationship is reversible.

In our exploratory empirical analysis, we have looked at 400 multilateral treaties and supplementary texts from the area of international environmental politics. We note that there are remarkable differences in the provisions for adoption and entry into force of amendments, as well as in the existence and use of third-party arbitration. Using correspondence analysis, we show that the provisions can be represented in two dimensions: one is the degree of explicit institutionalisation, the other is the degree of flexibility in collective decision making. Furthermore, it is shown that flexibility rules complement each other. Treaties which have more flexible amendment rules are also more likely to have binding arbitration procedures. This parallels the "checks and balances" applied within nations and suggests that constitution designers care for "bounded flexibility" on the international level.

Our empirical results mainly serve to establish some quantitative knowledge on flexibility rules, which has so far not been established in the literature, while a precise statistical test of our economic hypothesis is left to further research. Another avenue for further research could be to extend the universe of treaties investigated. Restricting the analysis to treaties dealing with a particular subject-matter, environmental problems, left us with considerable variation in some provisions for renegotiation. 
However, treaties were quite similar in other respects, such as the duration or the provisions concerning members not ratifying amendments. Our guess is that this may have to do with the economic character of the good provided by the treaty. Techniques such as loglinear modelling or hierarchical logistic regression models (Thurner, 1998, 2000) might be used for the statistical explanation of negotiators' choice of provisions, distinguishing between goods-induced, structure induced and institutionally induced factors. Finally, a third interesting topic for further analysis may concern the path dependence of the institutions under consideration. 


\section{References}

Aghion, P.; M: Dewatripont; P. Rey (1994), Renegotiation design with unverifiable information, Econometrica, 62, 257-282.

Amerasinghe, C.F. (1996): Principles of the institutional law of international organizations, Cambridge: University Press

Blasius, J. (2001), Korrespondenzanalyse, München: Oldenbourg.

Bourdieu, P. (1979), La distinction: critique sociale du jugement, Paris: Les Editions de Minuit.

Bowett, D.W. (1982): The law of international institutions, 4th ed., London: Stevens \& Sons.

Bowman, M.J. (1995), The multilateral treaty amendment process, a case study, International and Comparative Law Quarterly, 44, 540-559.

Burhenne, W.E. (ed.) (n.d.): International environmental law: multilateral treaties, Berlin.

Chasek, P. (2001), Earth negotiations: analyzing thirty years of environmental diplomacy, Tokyo: United Nations University Press.

Clausen, S.-E. (1998), Applied correspondence analysis: an introduction, Thousand Oaks: Sage.

Congleton, R.D. (1992), Toward a transactions cost theory of environmental treaties: substantive and symbolic environmental agreements, Economia delle scelte pubbliche, 2-3, 119-139.

Cooter, R. (2000), The strategic constitution, Princeton: University Press.

Giovannoni, F. (2001), Amendment rules in constitutions, Ms., University of Newcastle.

Gold, J. (1973): The amendment and variation of their charters by international organizations. Revue Belge de droit international, 10, 50-76.

Greenarce, M.J. (1993), Correspondence analysis in practice, London: Academic Press.

Grout, P. (1984), Investment and wages in the absence of binding contracts, a Nash bargaining approach, Econometrica, 52, 449-460.

Haffner, G. (1999), Kodifikation und Weiterentwicklung des Völkerrechts, in: Cede, F., et al. (eds.): Die Vereinten Nationen: Recht und Praxis, Wien: Manz; München: Beck.

Hart, O. ; J. Moore (1988), Incomplete contracts and renegotiation, Econometrica, 56, 755-785.

Hart, O. ; J. Moore (1990), Property rights and the nature of the firm, Journal of Political Economy, 98, 1119-1158.

Hirschman, A. O. (1970), Exit, voice, and loyalty: responses to decline in firms, organizations, and states, Cambridge, Mass.: Harvard University Press.

Ipsen, K., 1999: Völkerrecht, 4th ed., München: Beck. 
Jolls, C. (1997): Contracts as bilateral commitments: A new perspective on contract modification, Journal of Legal Studies, 26, 203-237.

Klein, B.; R.B. Crawford; A.A. Alchian (1978), Vertical integration, appropriable rents, and the competitive contracting process, Journal of Law and Economics, 21, 297-326.

Koremenos, B. (2001a): Loosening the ties that bind: a learning model of agreement flexibility, International Organization, 55, 289-325

Koremenos, B. (2001b): Modeling the adjustment mechanisms in international agreements, Ms., UCLA.

Kreps, D.M. (1979): A representation theorem for "Preference for flexibility ", Econometrica, 47, 565-577

Nöldeke, G.; K. Schmidt (1995), Option contracts and renegotiation, A solution to the hold-up proble, Rand Journal of Economics, 26, 163-179.

Raustiala, K. (2001), Compliance and effectiveness in international regulatory cooperation, Case Western Reserve Journal of International Law, 32, 453-508.

Ress, G. (1994), Ex ante safeguards against ex post opportunism in international treaties, Theory and practice of international law, Journal of Institutional and Theoretical Economics, 150, 279-303.

Rogerson, W.P. (1992), Contractual solutions to the hold-up problem, Review of Economic Studies, 59, 777-793.

Schermers, H. G.; Blokker, N. (1995), International institutional law: unity within diversity, 3rd. ed., The Hague: Martinus Nijhoff.

Schmitz, P.W. (2001), The hold-up problem and incomplete contracts: a survey of recent topics in contract theory, Bulletin of Economic Research, 53, 1-17.

Schwelb, E. (1954): The amending procedure of constitutions of international organizations in: British Yearbook of International Law, 31, 49-95

Shavell, S. (1998), Contracts, in: Newman, P. (ed.), The new Palgrave Dictionary of Economics and the Law, London: Macmillan, 436-445.

Stone Sweet, A. (1998), Comment on Vanberg: Rules, Dispute Resolution, and Strategic Behavior, Journal of Theoretical Politics, 10, 327-338.

Stone Sweet, A. (2000), Governing with judges: constitutional politics in Europe. Oxford: University Press.

Thurner, P.W. (1998), Wählen als rationale Entscheidung. Die Modellierung von Politikreaktionen im Mehrparteiensystem, München: Oldenbourg, Scientia Nova.

Thurner, P.W. (2000), The Empirical Application of the Spatial Theory of Voting in Multiparty Systems with Random Utility Models. Electoral Studies 19,4: 45-69.

Tirole, J. (1999), Incomplete contracts: Where do we stand, Econometrica, 67, 741781.

Vanberg, G. (1998), Abstract Judicial Review, Legislative Bargaining, and Policy Compromise, Journal of Theoretical Politics, 10, 299-326. 
Williamson, O.E. (1985), The economic institutions of capitalism: firms, markets, relational contracting, New York.

Zacklin, R. (1968): The amendment of the constitutive instruments of the United Nations and Specialized Agencies, Leyden : Sijthoff. 


\section{Appendix: Code book used for coding flexibility provisions}

\section{Code Definition Row Notation \\ number \\ (tabs. 3-5)}

\section{Provisions mentioning the number of parties to the treaty}

$\mathrm{A} X \quad$ explicit mentioning of $X$ contracting parties

$\mathrm{B} X \quad$ explicit mentioning of $X$ contracting parties, if accession of further parties is arranged for in the treaty

$0 \quad$ contracting parties are not mentioned in the treaty

\section{Provisions specifying limited duration or revision}

$\mathrm{CX}$ revision possible on request in $X$ years at the earliest

$\mathrm{R} X \quad$ revision scheduled in $X$ years

$\mathrm{B} X \quad$ treaty is limited in duration ( $X$ years)

$\mathrm{A} X \quad$ amendments are not permitted until expiration of $X$ years

0 no revision or limitation in duration of the treaty

\begin{tabular}{|c|c|c|c|}
\hline \multicolumn{4}{|c|}{ 3. Existence of amendment provisions } \\
\hline 1 & \multicolumn{3}{|l|}{ yes } \\
\hline 2 & \multicolumn{3}{|l|}{ only in the form of a revision } \\
\hline 0 & \multicolumn{3}{|l|}{ No } \\
\hline \multicolumn{4}{|c|}{ 4. Provisions for adoption } \\
\hline $\mathrm{X}$ & majority requirement for approval: $X$ per cent & 3 & qualified majority \\
\hline $\mathrm{B}$ & consensus & 2 & consensus \\
\hline $\mathrm{C}$ & unanimity & 1 & unanimity \\
\hline $\mathrm{D}$ & \multicolumn{3}{|l|}{ others or combinations } \\
\hline $\mathrm{E}$ & no provisions for adoption & 4 & not specified \\
\hline $\mathrm{F}$ & \multicolumn{3}{|l|}{$\begin{array}{l}\text { adoption according to the statute of an international } \\
\text { organisation }\end{array}$} \\
\hline G & no amendments & 4 & not specified \\
\hline \multicolumn{4}{|c|}{ 5. Provisions for entry into force } \\
\hline$X \mathrm{a}$ & $\begin{array}{l}\text { after ratification of } X \text { per cent of the signatories; then in force } \\
\text { for all states which have ratified }\end{array}$ & 2 & a majority ratifies \\
\hline$X \mathrm{~b}$ & $\begin{array}{l}\text { after ratification of } X \text { per cent of the signatories; then in force } \\
\text { for all states, except those that object explicitly }\end{array}$ & 2 & a majority ratifies \\
\hline$Y \mathrm{a}$ & $\begin{array}{l}\text { after ratification of } Y \text { signatories; then in force for all states } \\
\text { which have ratified }\end{array}$ & 2 & a majority ratifies \\
\hline$Y \mathrm{~b}$ & $\begin{array}{l}\text { after ratification of } Y \text { signatories; then in force for all states, } \\
\text { except those that explicitly object }\end{array}$ & 2 & a majority ratifies \\
\hline A & enters into force for all members without separate ratification & 4 & no separate procedure \\
\hline $\mathrm{B}$ & $\begin{array}{l}\text { enters into force for all members without separate ratification } \\
\text { unless a minimum number of states objects }\end{array}$ & 3 & $\begin{array}{l}\text { no ratification, but } \\
\text { objection is possible }\end{array}$ \\
\hline $\mathrm{C}$ & $\begin{array}{l}\text { enters into force for all members without ratification except } \\
\text { for those that explicitly object }\end{array}$ & 4 & no separate procedure \\
\hline $\mathrm{D}$ & enters only into force if all parties ratify & 1 & all ratify \\
\hline $\mathrm{E}$ & other rules & & \\
\hline $\mathrm{F}$ & according to the statute of an international organisation & & \\
\hline
\end{tabular}




\section{Code book used for coding flexibility provisions (continued)}

\begin{tabular}{llcl} 
Code & Definition & $\begin{array}{l}\text { Row } \\
\text { number } \\
\text { (tabs. 3-5) }\end{array}$ & Notation \\
\hline $\mathrm{G}$ & not mentioned & 5 & not specified \\
$\mathrm{G}$ & not mentioned & 5 & no amendments \\
$\mathrm{H}$ & $\begin{array}{l}\text { enters into force for all members without ratification except } \\
\text { for those objecting explicitly, unless a minimum number of } \\
\text { states object }\end{array}$ & 3 & no ratification, but \\
& ebjection is possible \\
I & of a minimum number & & \\
\hline
\end{tabular}

\section{Outcome for parties not ratifying the amendment}

0 not mentioned

1 remain bound by the original treaty

2 possibly have to leave the treaty

\section{Arbitration procedure ${ }^{i}$}

$\begin{array}{ll}\text { A } & \text { permanent arbitral tribunal } \\ \text { B } & \text { other (e.g. ad-hoc) arbitral tribunal } \\ \text { C } & \text { conciliation or mediation commission } \\ \text { D } & \text { International Court of Justice } \\ \text { E } & \text { arbitration institutions of an International Organisation or } \\ & \text { another treaty } \\ \text { F } & \text { others, explicitly mentioned } \\ \text { G } & \text { others, not explicitly mentioned } \\ \text { H } & \text { no institutions for arbitration } \\ \text { I } & \text { convention of the member states }\end{array}$

8. Legal liability of the outcome of dispute resolution

\begin{tabular}{lll} 
A & final and binding & 1 \\
B & recommendation & 2 \\
C & no dispute resolution & 3 \\
\hline
\end{tabular}

\section{Scope of dispute resolution procedure}

\begin{tabular}{ll} 
A & whole treaty \\
B & limited \\
C & not applicable \\
\hline \hline
\end{tabular}

i If a treaty includes different provisions for differentiated groups of participants, only the most restrictive provision is taken into account for the coding.

ii Multiple entries are possible during the coding procedure, for the aggregation only the arbitration procedure with the highest degree of institutionalisation is considered. 